\title{
Estimates of Occupational Cancer in Korea
}

\author{
Soo-Hun $\mathrm{CHO}^{1}$, Daehee $\mathrm{KANG}^{1}$, Kyung-Sim $\mathrm{Ko}^{2}$, Ho-Jang $\mathrm{KwON}^{3}$, Dong-Hyun $\mathrm{KIM}^{4}$, \\ Mina $\mathrm{HA}^{3}$, Sang-Hwan $\mathrm{HAN}^{5}$ and Yeong Su Ju${ }^{1}$ \\ ${ }^{1}$ Department of Preventive Medicine, Seoul National University College of Medicine, ${ }^{2}$ Department of Obstet- \\ rics and Gynecology, Dankuk University College of Medicine, ${ }^{3}$ Department of Preventive Medicine, Dankuk \\ University College of Medicine, ${ }^{4}$ Department of Social Medicine, Hallym University College of Medicine and \\ ${ }^{5}$ Gill Hospital Institute for Occupational Medicine
}

\begin{abstract}
Estimates of Occupational Cancer in

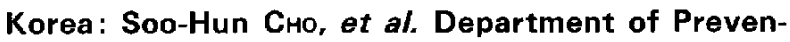
tive Medicine, Seoul National University College of Medicine-An accurate estimation of the contribution of occupational exposure to cancer is very difficult. In order to evaluate the magnitude of the problem of occupational cancer in Korea, the numbers of these cancers were estimated. A panel of physicians was asked to complete a questionnaire survey asking about potentially important occupational cancers. The numbers of occupation-related cancers in Korea were estimated, based on the numbers of emoloyees exposed to selected occupational carcinogens, the relative risks of affected cancers among exposed employees, and the incidence of those cancers among the general population. More than $90 \%$ of physicians who participated in the survey indicated their belief that many occupational cancers have occurred previously without being detected. Preventive medicine specialists reported a greater contribution $(5-30 \%)$ than clinical oncologists and cancer surgeons (1-10\%) of occupational exposure to cancer. Participant physicians indicated that lung, bladder, hematopoietic and skin cancer will in the future be major occupational cancers in Korea. The reported chemicals and industries in which occupational cancer will be important included asbestos, petrochemicals, benzene, dyes, radiation, coke oven emissions, polycyclic aromatic hydrocarbons, plating work, and chrome. The estimated annual total of occupational cancer cases in Korea was 5-28 after subtracting the number of cases in the general population from the number among employees exposed to occupational carcinogens. Although this study has several limitations, it was the first attempt to estimate the number of cases of occupational cancer in Korea. Future studies to accurately estimate the
\end{abstract}

Received Aug 1, 1996; Accepted Dec 9, 1996

Correspondence to: S. $\mathrm{H}$. Cho, Department of Preventive Medicine, Seoul National University College of Medicine, 28 Yongon-Dong, Chongno-Gu, Seoul 110-799, Korea number of employees exposed to occupational carcinogens and to link the existing database on cancer occurrence (e.g. cancer registry, medical insurance data, etc.) with exposure data are needed. (J Occup Health 1997; 39: 192-196)

Key words: Occupational cancer, Korea

Since Sir Percivall Pott, in 1775, first linked cancer of the scrotum among chimney sweepers to their occupational exposure, there have been numerous reports delineating the relationship between occupational exposure and cancer occurrence, but only a limited number of studies have provided the information on the magnitude of the problem of occupational exposure to carcinogens and the contribution of occupational exposure to cancer. The National Institute for Occupational Safety and Health (NIOSH) in the United States indicates that 110,000 workers are potentially exposed to the 21 chemicals currently regulated as carcinogens by the U.S. Occupational Safety and Health Administration (OSHA) ${ }^{1)}$. If those agents not presently regulated by OSHA but recommended by NIOSH for regulation are added, a total of between three and nine million workers in the United States may be exposed to carcinogens ${ }^{2}$.

Estimates of the fraction of cancers with occupational origin range from $1 \%$ to $38 \%{ }^{37}$. An accurate estimation of the contribution of occupational exposure to cancer is very difficult, however. There are several reasons for this, such as inadequate knowledge of exposure in the workplace to a combination of carcinogenic substances, nonspecific manifestation of occupational cancer, incomplete exposure assessment, and a lack of the understanding of the interaction between occupational and non-occupational causes of cancer ${ }^{4}$.

Korea has achieved rapid economic growth over 
the last three decades and the distribution and patterns of diseases have also become westernized. In 1992, cancer became the leading cause of death in Korea ${ }^{5)}$. Two recent incidents a case of mesothelioma in a worker exposed to asbestos, and a case of leukemia due to exposure to benzene-recently drew enormous public interest in Korea and also generated scientific controversy in determining the work-relatedness of these occurrences. Only a few cancer cases have so far been compensated, however, partly because of the lack of information on past exposure of employees to carcinogens, and the extent of the contribution in Korea of occupational exposure to cancer.

In order to determine the magnitude of the problem, a panel of physicians was asked to complete a questionnaire survey about the future potential of important cancers. The numbers of occupationrelated cancers in Korea were estimated. These results will provide baseline information to determine the work-relatedness of these devastating diseases, to set up priority guidelines to reduce the occurrence of such cancers and finally to help us reallocate limited resources in the field of occupational health research in Korea.

\section{Methods}

\section{A questionnaire survey concerning potentially} important occupation-related cancers in Korea

A questionnaire survey was conducted to assess the extent of potentially important occupational cancer in Korea. First, a group of physicians who specialize in preventive medicine, clinical oncology and cancer surgery were selected. Inclusion was based on medical education, age, duration of practice and sub-specialty, and the membership directories of the Korean Society of Preventive Medicine and the Korean Society for Oncology were also used. Second, a self-administered questionnaire about their opinions on the type, causes, and control and prevention of occupational cancer was used to assess potentially important occupational cancer in Korea. The total number of physicians asked to participate in the survey was 146 . These included 62 preventive medicine specialists (PM) and 84 medical oncologists and cancer surgeons (CA). The overall response rate was $56 \%$ (82/ 146) after return of the questionnaire was solicited twice. There was no significant difference in the response rate between PM specialists and CA physicians. PM specialists were asked nine questions items, and CA physicians were asked six, excluding three specific questions regarding the strategies of cancer prevention and control.

\section{Estimates of the numbers of occupation-related cancer cases in Korea}

The numbers of occupation-related cancer cases in Korea were estimated by sequential use of the following information: 1) the numbers of employees exposed to selected carcinogens, 2) relative risks of cancers among exposed employees, 3) incidence of these cancers among exposed employees, and 4) incidence of these cancers among the general population. First, a number of occupational carcinogens known to expose workers to high risk were selected. Second, the numbers of employees over 40 years old exposed to the selected carcinogens were estimated. Third, the extent of cancer occurrence among these employees was calculated by subtracting the number of cancer cases among the general population from the number of cases among exposed employees. The number of cancer cases among this latter group was estimated by multiplying the relative risks of cancers known to be related to those carcinogens by the number of cancer cases among the general population.

\section{Results}

1. A questionnaire survey concerning potentially important occupation-related cancers in Korea

Among 82 physicians who participated in the questionnaire survey were 25 environmental and occupational medicine specialists, 18 hematooncologists, seven general internists, seven general surgeons, six epidemiologists and five cancer surgeons; more than half of the total had practiced medicine for more than 16 years. Although there was a slight difference in the order of importance of types of cancers, both preventive medicine specialists (PM) and medical oncologists and cancer surgeons (CA) reported that lung, colo-rectal, breast, liver and hematopoietic cancers were the top five most potentially important cancers in Korea (Table 1). They also indicated that in the future, lung, bladder, hematopoietic and skin caner will be the most important occupational cancers in Korea (Table 2). It was reported that their increasing occurrence will be most significantly attributable to

Table 1. Type of potentially important cancers in Korea reported by physicians participating in the questionnaire survey

\begin{tabular}{lcc}
\hline Type of cancer & $\begin{array}{c}\text { Preventive medicine } \\
\text { specialists } \\
\% \text { (ranking) }\end{array}$ & $\begin{array}{c}\text { Oncologists \& cancer } \\
\text { surgeons } \\
\% \text { (ranking) }\end{array}$ \\
\hline Lung & $33(1)$ & $30(1)$ \\
Colo-rectal & $21(2)$ & $21(3)$ \\
Breast & $15(3)$ & $23(2)$ \\
Liver & $11(4)$ & $4(5)$ \\
Hematopoietic & $4(5)$ & $6(4)$ \\
\hline
\end{tabular}


Table 2. Type of potentially important occupational cancers in Korea reported by participant physicians

\begin{tabular}{lcc} 
Type of cancer & $\begin{array}{c}\text { Preventive medicine } \\
\text { specialists } \\
\text { \% (ranking) }\end{array}$ & $\begin{array}{c}\text { Oncologists \& cancer } \\
\text { surgeons } \\
\text { \% (ranking) }\end{array}$ \\
\hline Lung & $27(1)$ & $30(1)$ \\
Bladder & $14(2)$ & $10(3)$ \\
Hematopoietic & $14(3)$ & $17(2)$ \\
Skin & $11(4)$ & $9(4)$ \\
Liver & $10(5)$ & $4(6)$ \\
\hline
\end{tabular}

Table 3. Major environmental risk factors reported by participant physicians

\begin{tabular}{lcc}
\hline $\begin{array}{c}\text { Environmental } \\
\text { risk factors }\end{array}$ & $\begin{array}{c}\text { Preventive medicine } \\
\text { specialists } \\
\% \text { (ranking) }\end{array}$ & $\begin{array}{c}\text { Oncologists \& cancer } \\
\text { surgeons } \\
\% \text { (ranking) }\end{array}$ \\
\hline $\begin{array}{l}\text { Increased use of } \\
\text { carcinogens }\end{array}$ & $27(1)$ & $11(4)$ \\
Air pollution & $23(2)$ & $28(1)$ \\
Smoking & $10(3)$ & $15(3)$ \\
Water pollution & $8(4)$ & $6(5)$ \\
Diet & $8(4)$ & $24(2)$ \\
\hline
\end{tabular}

diet, smoking, environmental pollution, the increased use of carcinogens, change in life style and increased life expectancy. Although there were slight discrepancies in the order of significance of potentially important environmental risk factors, both PM and CA reported their belief that the increased use of carcinogens, air and water pollution, smoking and diet were most important (Table 3).

More than $90 \%$ of both PM and CA indicated that many occupational cancers in Korea have occurred previously without being detected. PM reported a greater contribution (5-30\%) than $\mathrm{CA}$ (1-10\%) of occupational exposure to cancer. The chemicals and industries in which occupational cancer will be important future problems include asbestos, petrochemicals, benzene, dyes, radiation, coke oven emissions, polycyclic aromatic hydrocarbons, plating work and chrome. On the question of preventive strategies, $P M$ indicated that control of the working environment, education of employees, regulation and management of occupational carcinogens, medical surveillance and the use of the proper protective equipment are the most important approaches.

\section{Estimates of the numbers of occupation-related cancer cases in Korea}

Nine occupational carcinogens were selected to estimate the annual incidence of cases of occupational cancers based on the results of the opinion survey in which the physicians identified them as the priority chemicals needed to be controlled and the numbers of exposed employees in the work environment survey for the manufacturing industries conducted by the Korea Industrial Safety Corporation (KISCO) in $1993^{6}$. The types of carcinogens identified as the priority chemicals from the opinion survey were almost identical with those in the results of the work environment survey and these included asbestos, chrome, vinyl chloride, coke oven emissions, benzidine, arsenic, benzene, nickel and wood dusts. Table 4 summarizes the estimated total number of employees potentially exposed to these carcinogens, which in 1993 was approximately 37,000 . Of these, only employees over 40 were listed as 'exposed' because most occupational cancers have a latency period of at least 15-20 years and the incidence of cancers is relatively low in the Korean population under 40. Approximately 9,000 employees over 40 years old were potentially exposed to these nine carcinogens (Table 5).

The estimated annual total of occupational cancer cases in Korea was 5-28 after subtracting the number of cancer cases among the general population from the number of cases among exposed em-

Table 4. Estimated numbers of employees exposed to selected carcinogens in Korea in $1993^{6)}$

\begin{tabular}{|c|c|c|c|c|c|c|c|}
\hline \multirow{2}{*}{ Selected carcinogens } & \multicolumn{2}{|c|}{ Manufacturing } & \multicolumn{2}{|c|}{ In use } & \multicolumn{2}{|c|}{ By-products } & \multirow{2}{*}{$\begin{array}{l}\text { Total No. of } \\
\text { employees }\end{array}$} \\
\hline & $\begin{array}{c}\text { No. of } \\
\text { workplaces }\end{array}$ & $\begin{array}{c}\text { No. of } \\
\text { employees }\end{array}$ & $\begin{array}{c}\text { No. of } \\
\text { workplaces }\end{array}$ & $\begin{array}{c}\text { No. of } \\
\text { employees }\end{array}$ & $\begin{array}{c}\text { No. of } \\
\text { workplaces }\end{array}$ & $\begin{array}{c}\text { No. of } \\
\text { employees }\end{array}$ & \\
\hline Wood dust & 0 & 0 & 4 & 106 & 1,720 & 14,268 & 14,374 \\
\hline Nickel & 1 & 11 & 292 & 1,374 & 13 & 6,297 & 7,671 \\
\hline Chrome & 0 & 0 & 311 & 2,311 & 8 & 6,320 & 8,631 \\
\hline Benzene & 8 & 285 & 531 & 2,894 & 20 & 1,317 & 4,496 \\
\hline Coke oven emissions & 3 & 801 & 54 & 518 & 1 & 16 & 1,335 \\
\hline Asbestos & 0 & 0 & 46 & 718 & 4 & 44 & 762 \\
\hline Vinyl chloride & 3 & 95 & 5 & 127 & 5 & 26 & 248 \\
\hline Benzidine & 3 & 52 & 14 & 118 & 0 & 0 & 170 \\
\hline Arsenic & 0 & 0 & 4 & 43 & 0 & 0 & 43 \\
\hline Total & 18 & 1,244 & 1,261 & 8,209 & 1,771 & 28,288 & 37,730 \\
\hline
\end{tabular}


Table 5. Estimated numbers of annual occurrence of occupational cancer in Korea

\begin{tabular}{|c|c|c|c|c|c|c|c|}
\hline Carcinogen & $\begin{array}{l}\text { Types of cancer } \\
\text { related to these } \\
\text { carcinogens }\end{array}$ & $\begin{array}{l}\text { Estimated No. } \\
\text { of exposed } \\
\text { employees } \\
\text { over } 40(a)^{6)}\end{array}$ & $\begin{array}{l}\text { Relative risk } \\
\text { (b) }^{8-12)}\end{array}$ & $\begin{array}{c}\text { Baseline } \\
\text { incidence in } \\
\text { Korean } \\
\text { population } \\
\text { over } 40 \\
(/ 100,000) \\
(\mathrm{c})\end{array}$ & $\begin{array}{l}\text { Estimated } \\
\text { incidence of } \\
\text { cancer in } \\
\text { exposed } \\
\text { employees } \\
(\mathrm{d}=\mathrm{a} * \mathrm{~b} * \mathrm{c})\end{array}$ & $\begin{array}{c}\text { Baseline } \\
\text { incidence in } \\
\text { exposed } \\
\text { employees } \\
(e=a * c)\end{array}$ & $\begin{array}{c}\text { Excess } \\
\text { incidence of } \\
\text { cancer in } \\
\text { exposed } \\
\text { employees } \\
(\mathbf{f}=\mathrm{d}-\mathrm{e})\end{array}$ \\
\hline Asbestos & Lung & 198 & $1.5-12$ & 55.3 & $0.16-1.31$ & 0.11 & $0.05-1.20$ \\
\hline Chrome & Lung & 2,246 & 4-20 & 55.3 & $4.97-24.8$ & 1.24 & $3.73-23.6$ \\
\hline Vinyl chloride & Liver & 65 & $3.2-12$ & 75.5 & $0.16-0.59$ & 0.05 & $0.11-0.54$ \\
\hline Coke oven emissions & Lung & 347 & 2.7 & 55.3 & 0.5 & 0.18 & 0.32 \\
\hline Benzidine & Bladder & 44 & 14 & 12.5 & 0.08 & 0.01 & 0.07 \\
\hline Arsenic & Lung & 11 & $2.3-8$ & 55.3 & $0.01-0.05$ & 0.01 & $0.00-0.04$ \\
\hline Benzene & Leukemia & 1,169 & 2.5 & 4.4 & 0.13 & 0.05 & 0.08 \\
\hline Nickel & Sinus & 1,994 & $4-20.5$ & 2.7 & $0.22-1.11$ & 0.05 & $0.10-0.63$ \\
\hline Wood dusts & Sinus & 3,737 & $2.5-14.1$ & 2.7 & $0.25-1.44$ & 0.10 & $0.15-1.34$ \\
\hline Total & & 9,811 & & & & & $4.61-27.82$ \\
\hline
\end{tabular}

ployees (Table 5). The number of cancer cases among the general population was estimated by referring to the Seoul Cancer Registry); the number of cases among exposed employees was estimated by multiplying the relative risks of cancers known to be related to the carcinogens mentioned by the number of cases among the general population. The ranges of relative risks of cancers known to be related to these carcinogens were selected from previously conducted epidemiological studies in other countries ${ }^{8-12)}$ since we do not have any epidemiological data relating to occupational cancer in Korea.

\section{Discussion}

This study has several limitations. First, the numbers of employees potentially exposed to selected occupational carcinogens may be incorrect or underestimated because the survey results used to calculate exposed employees cover only about $70 \%$ of the manufacturing industries in Korea and the estimated number of employees involved in the process of manufacturing or using the chemicals was used as the number of exposed employees instead of calculating the number of employees actually exposed. Second, employees older than 40 were arbitrarily selected because most occupational cancer has a latency period of at least 15-20 years and the incidence of cancers is relatively low in the Korean population under 40; more importantly, no information was available on the turn-over rates of employees in different industries or on the job history of each individual (e.g., how many years employed in each job during the entire work history). Third, the relative risks used to calculate the excess numbers of cancer occurrence in this study were taken from the results of previous epidemiologic studies conducted in other countries and derived in occupations and industries which might be different from the structure and type of industries in Korea. Fourth, the total number of occupational cancers in this study may be underestimated because only current employees were included in the calculations. In general, many employees who have cancer or other significant clinical problems leading to cancer have already left work and were not included in the denominators in this study.

The opinion survey in this study to evaluate the magnitude of the problem of occupational cancer in the future also contains several limitations. First, although the survey participants were originally selected on the basis of the lists provided by the professional societies (e.g., preventive medicine and oncology), potential selection bias due to a low response rate even after two solicitation letters was not evaluated. Although the reason for the low response rate was not evaluated, the response rate in this study was similar to the rate reported in other studies using mailing questionnaires conducted in Korea. Second, the results of the opinion survey used in this study to identify the future trend of occupational cancer in Korea are vulnerable to several factors such as the characteristics of respondents and the validity of the information collected. They can, however, be used as the first step in identifying the priority area in occupational cancer since there was no information available on the changes in the scope and magnitude of occupational hazards linked to cancer development in Korea.

In spite of these limitations and the underreporting of occupational cancer indicated by studies in other countries, these results, showing the estimated annual occurrence of occupational cancer 
(5-28), are far lower than the compensated cancer cases reported from other countries including Japan (about 60 compensated cancer cases per year) ${ }^{13)}$, Canada (550 compensated cases from three provinces-British Columbia, Saskatchewan, and Ontario - from 1980 to 1989$)^{14)}$, Denmark (92 reported cases of mesothelioma and sinonasal adenocarcinoma from 1983 to 1987$)^{15)}$, Germany (291 compensated cases in 1986) ${ }^{16)}$, and France (101 compensated cases in 1986) ${ }^{17}$.

Although this study has several limitations, it was the first attempt to estimate the number of cases of occupational cancer in Korea and these results provide baseline information on the magnitude of the problem. For a more accurate understanding of this, several future studies are needed. First, an accurate estimation of employees exposed to occupational carcinogens is important. In addition to information relating to their occupational history (e. g. job, task, process, duration, etc.), information on their personal life style (e.g. smoking and diet) should also be collected. The hazard surveillance system for occupational carcinogens should be implemented. Second, the standardized case definition or generalized diagnostic criteria of occupational cancer should be used since reliable and valid outcome measures are critical in epidemiologic studies of occupational cancer. Third, a linkage study of existing databases on cancer occurrence (e.g., cancer registry, medical insurance data, etc.) with exposure data is needed.

This project was partially supported by the Korean Ministry of Labor for Preventing Occupational Diseases.

\section{References}

1) U.S. Department of Health, Education and Welfare. National occupational hazard survey. DHEW (NIOSH) Publication No. 78-114. Cincinnati, OH : National Institute for Occupational Safety and Health, 1978.

2) U.S. Department of Health and Human Services. Proposed national strategies for the prevention of leading work-related diseases and injuries: Occupational cancers. DHHS (NIOSH) Publication No. 89 -130 . Cincinnati, $\mathrm{OH}$ : National Institute for Occupational Safety and Health, 1986.

3) Vineis P, Simonato L. Proportion of lung and bladder cancers in males resulting from occupation: A systematic approach. Arch Environ Health 1991; 46: 6-15.

4) Gardner MJ. Contribution of occupational exposure to cancer: Recent developments. Br J Ind Med $1991 ; 48: 217-220$.

5) Korean Ministry of Health and Social Affairs. Yearbook of health and social statistics. 1992.

6) Korea Industrial Safety Corporation (KISCO).
Results of a survey of work environment in the manufacturing industries. 1994.

7) Kim JP, Park IS, Ahn YO, et al. 1991 cancer incidence in Seoul, Korea: Results of the implementation study of the Seoul Cancer Registry. J Korean Medical Science 1995; 10: 74-94.

8) Waxweiler RJ, Coller PF. Neoplastic risk among workers exposed to vinyl chloride. Ann New York Acad Sci 1976; 271-280.

9) Kaldor J, Peto J, Easton D, et al. Models for respiratory cancer in nickel refinery workers. JNCI 1986; $77: 841$.

10) Nylander LA, Dement JM. Carcinogenic effects of wood dusts: Review and Discussion. Am J Ind Med 1993; 24: 619-647.

11) Samet JM, Lerchen ML. Proportion of lung cancer caused by occupation: A critical review. In: Gee JBL, Morgan KC, Brooks SM, eds., Occupational lung disease. New York: Raven Press, 1984: 55-67.

12) Peto R, Schneiderman M. Quantitation of occupational cancer. Banbury Report 9. Cold Spring Harbor, NY: Cold Spring Harbor Laboratory, 1981: 701-726.

13) Tsuchiya K. Occupational health in Japan. The OEM Report, July, 1994.

14) Teschke K, Barroetavena MC. Occupational cancer in Canada: What do we know? Can Med Assoc J 1992; 147: 1501-1507.

15) Skov T, Mikkelsen S, Svane O, Lynge E. Reporting of occupational cancer in Denmark. Scand J Work Environ Health 1990; 16: 401-405.

16) Gaffuri E. Disparity between estimated numbers and reported cases of occupational cancer $\lfloor$ Letters to the Editor7. Scand J Work Environ Health 1991; 17: 216-217.

17) Landrigan PJ, Markowitz S. Current magnitude of occupational disease in the United States: Estimates from New York State. Ann New York Acad Sci $1989 ; 572: 27-45$.

Appendix : The questionnaire used in the opinion survey

1. Please list three cancers which will be important in the future in Korea.

2. Please list three reasons why cancers listed above will be important.

3. Please list three important environmental factors related to cancer development.

4. What proportion do you think that occupation contributes to all cancer occurrence?

5. Do you think that occupational cancers have occurred previously in Korea?

6. Please list three occupational cancers which will be important in the future in Korea.

For the preventive medicine specialists only:

7. Please list three measures for preventing occupational cancer in Korea.

8. Please indicate three industries in which measures to control occupational cancer will be needed.

9. Please list three chemicals which might contribute to the occurrence of occupational cancer. 